\title{
Accumulation of fibronectin in the heart after myocardial infarction: a putative stimulator of adhesion and proliferation of adipose-derived stem cells
}

\author{
A. van Dijk • H. W. M. Niessen • W. Ursem • \\ J. W. R. Twisk • F. C. Visser • F. J. van Milligen
}

Received: 25 April 2007 / Accepted: 9 January 2008 / Published online: 28 February 2008

(C) Springer-Verlag 2008

\begin{abstract}
Stem cell therapy is a promising treatment after myocardial infarction (MI). A major problem in stem cell therapy, however, is that only a small proportion of stem cells applied to the heart can survive and differentiate into cardiomyocytes. We hypothesized that fibronectin in the heart after MI might positively affect stem cell adhesion and proliferation at the site of injury. Therefore, we investigated the kinetics of attachment and proliferation of adipose-tissue-derived stem cells (ASC) on fibronectin and analysed the time frame and localization of fibronectin accumulation in the human heart after MI. ASCs were seeded onto fibronectin-coated and uncoated culture wells. The numbers of adhering ASC were quantified after various incubation periods (5-30 min) by using DNA quantification
\end{abstract}

This study was supported by the Institute for CardioVascular Research of the VU Medical Centre in Amsterdam, the Netherlands (ICaR-VU), project 200380.

A. van Dijk $(\bowtie) \cdot H$. W. M. Niessen • W. Ursem •

F. J. van Milligen

Department of Pathology, ICaR-VU, VU University Medical Centre,

Boelelaan 1117, 1081 HV Amsterdam, The Netherlands

e-mail: Annemieke.vandijk@vumc.nl

\section{H. W. M. Niessen}

Department of Cardiac Surgery, VU University Medical Centre, Amsterdam, The Netherlands

J. W. R. Twisk

Department of Clinical Epidemiology and Biostatistics,

VU University Medical Centre, Amsterdam, The Netherlands

F. C. Visser

Department of Cardiology, VU University Medical Centre,

Amsterdam, The Netherlands

A. van Dijk · H. W. M. Niessen · F. C. Visser

ICaR-VU, Institute of Cardiovascular Research,

VU University Medical Centre, Amsterdam, The Netherlands assays. The proliferation of ASC was quantified after culturing ASC for various periods ( $0-9$ days) by using DNA assays. Fibronectin accumulation after MI was quantified by immunohistochemical staining of heart sections from 35 patients, after different infarction periods (0-14 days old). We found that ASC attachment and proliferation on fibronectin-coated culture wells was significantly higher than on uncoated wells. Fibronectin deposition was significantly increased from $12 \mathrm{~h}$ to 14 days post-infarction, both in the infarction area and in the borderzone, compared with the uninfarcted heart. Our results suggest that a positive effect of fibronectin on stem cells in the heart can only be achieved when stem cell therapy is applied at least $12 \mathrm{~h}$ after MI, when the accumulation of fibronectin occurs in the infarcted heart.

Keywords Stem cell · Heart · Adhesion · Infarction · Adipose tissue $\cdot$ Human

\section{Introduction}

Cardiovascular diseases are a leading cause of morbidity and mortality in the western world (Wang and Sjoquist 2006), with heart failure attributable to myocardial infarction (MI) being the most common aetiology ( $\mathrm{Lu}$ et al. 2004). Heart failure partly is caused by the loss of cardiomyocytes and the limited capacity of spontaneous regeneration of the heart. This results in the replacement of injured myocardium by scar tissue, which adversely affects cardiac function (Smits et al. 2005; Wang and Sjoquist 2006).

To reduce heart failure after MI, current therapeutic strategies focus on the restoration of the blood flow to the myocardium and on reducing cardiac remodelling by using drug therapy (inhibitors of angiotensin-converting enzyme 
and beta blockers; Fraser et al. 2004). Although these strategies significantly reduce mortality (Khalil et al. 2001; Lange and Hillis 2002), they do not replace the lost cardiomyocytes.

A promising tool to restore contractile function after myocardial infarction is stem cell therapy. Stem cells not only restore neovascularization, but also replace lost cardiomyocytes, since they have the capacity to differentiate into cardiomyocytes (Orlic et al. 2001; Strauer et al. 2002; Wang and Sjoquist 2006). However, to restore contractile function of the heart effectively after MI, sufficient stem cells need to attach to the infarcted area and subsequently proliferate and differentiate into cardiomyocytes, thereby replacing a substantial fraction of the jeopardized cardiomyocytes. Unfortunately, recent studies suggest that only a small proportion of stem cells applied to the heart invade the infarcted area and finally differentiate into cardiomyocytes. Furthermore, most of the applied stem cells die within the first week after transplantation (Wang and Sjoquist 2006; Zhang et al. 2001).

This high stem cell death rate is probably caused by the inferior environment that is found in the heart after myocardial infarction and into which the cells are transplanted; this poor environment is caused by the presence of inflammatory mediators and ischemia (Azarnoush et al. 2005; Wang and Sjoquist 2006; Zhang et al. 2001). Therefore, stem cell therapy has to be applied at that moment after infarction when the environment is most favourable for stem cell adhesion and cardiomyocyte formation. However, to the best of our knowledge, this ideal time frame has yet not been determined (Mishra 2005). In most animal studies, investigators apply stem cells during the same operational procedure as the infarct induction, whereas recent studies have shown that later time points might be more favourable for the survival of the stem cells (Bermejo et al. 2006; Lu et al. 2004; Wang and Sjoquist 2006).

Homing, growth and differentiation of stem cells after myocardial infarction is known to depend on several environmental factors, including the presence of adhesion factors at the site of injury (Chastain et al. 2006; Lu et al. 2004; Malek et al. 2006; Salasznyk et al. 2004; Wang and Sjoquist 2006). Fibronectin has been demonstrated to enhance the attachment of bone-marrow-derived stem cells in vitro, compared with several other extracellular matrix (ECM) molecules (Cool and Nurcombe 2005; Ogura et al. 2004). Fibronectin is a large molecular weight glycoprotein, present at low levels in the ECM of the healthy heart (Heng et al. 2004; Willems et al. 1996). In addition to the influence of fibronectin on cell attachment, the presence of fibronectin can also affect stem cell behaviour such as migration and proliferation, both in vitro and in vivo (Tate et al. 2002; van der Loo et al. 1998; Voermans et al. 1999;
Wijelath et al. 2004). However, the effect of fibronectin on adipose-tissue-derived stem cells (ASC) has as yet not been investigated. Therefore, we have examined whether fibronectin stimulates the attachment of ASC and have compared this with the attachment of ASC to other ECM proteins that are normally expressed in the heart and that are upregulated after acute MI (AMI), namely collagen type 1 and laminin (Deten et al. 2001; Morishita et al. 1996). We have also investigated the effect of fibronectin on the proliferation of ASC in vitro.

In vivo, fibronectin is strongly upregulated in the heart after MI (Froen and Larsen 1995; Knowlton et al. 1992; Willems et al. 1996). We have hypothesized that fibronectin serves as an attractant for ASCs, thereby improving stem cell homing, attachment and proliferation. Therefore, we have studied the kinetics and the localization of fibronectin accumulation in the human heart after MI in detail, in heart sections from 35 patients, representing various infarction periods.

\section{Materials and methods}

Adipose tissue donors

Human subcutaneous adipose tissue samples were obtained as waste material after elective surgery and donated upon informed consent of the patients from various clinics in Amsterdam, The Netherlands. Adipose tissue was harvested from the abdomen or hip and thigh region by using either resection or tumescent liposuction. Five donors (age-range: $27-49$ years) were included in this study.

Isolation of the stromal vascular fraction of adipose tissue

Adipose tissue was stored in sterile phosphate-buffered saline (PBS) at $4{ }^{\circ} \mathrm{C}$ and processed within $24 \mathrm{~h}$ after surgery as described previously (Oedayrajsingh-Varma et al. 2006). In brief, resected material was minced by using a surgical scalp before processing. After extensive washes with PBS, the ECM was enzymatically digested with $0.1 \%$ collagenase A (Roche Diagnostics, Mannheim, Germany) in PBS containing $1 \%$ bovine serum albumin (BSA; Roche Diagnostics) under intermittent shaking for $45 \mathrm{~min}$ at $37^{\circ} \mathrm{C}$. Then the material was washed with Dulbecco's modified Eagle's medium (DMEM-glucose; BioWhittaker, Cambrex, Verviers, Belgium) containing $10 \%$ fetal bovine serum (FBS) and centrifuged for $10 \mathrm{~min}$ at $600 \mathrm{~g}$. The cell pellet was resuspended in PBS and passed through a $200-\mu \mathrm{m}$ mesh (Braun/Beldico, Marche-en-Famenne, Belgium) to obtain a single cell suspension. To remove contaminating erythrocytes, the cells were subjected to Ficoll density centrifugation (lymphoprep, $\rho=1.077 \mathrm{~g} / \mathrm{ml}$, osmolarity: $280 \pm 15 \mathrm{mOsm}$; Axis-Shield, Oslo, Norway). The cell-containing interface 
was harvested and washed with DMEM containing $10 \%$ FBS. Cells were frozen under "controlled rate" conditions and stored in liquid nitrogen until needed in experiments.

\section{Cell culture}

Cells from the stromal vascular fraction were seeded at $1 \times 10^{5}$ cells $/ \mathrm{cm}^{2}$ and cultured for several passages in DMEM supplemented with $10 \%$ FBS, $100 \mathrm{U} / \mathrm{ml}$ penicillin, $100 \mu \mathrm{g} / \mathrm{ml}$ streptomycin, $2 \mathrm{mM}$ L-glutamine (all from Gibco, Invitrogen, Calif., USA; normal culture medium), in a humidified atmosphere of $5 \% \mathrm{CO}_{2}$ at $37^{\circ} \mathrm{C}$. Media were changed twice a week. When reaching $80 \%-90 \%$ confluency, cells were detached with $0.5 \mathrm{mM}$ EDTA $/ 0.05 \%$ trypsin (Gibco, Invitrogen) for $5 \mathrm{~min}$ at $37^{\circ} \mathrm{C}$ and replated.

\section{Attachment of ASC}

To investigate attachment of ASC to different coatings, culture-expanded cells (passages 3-6; p3-6) were seeded in a 96-well culture plate at a density of 25,000 cells per well. Wells were either uncoated or coated with fibronectin (5 or $0.5 \mu \mathrm{g} / \mathrm{cm}^{2}$; Roche Diagnostics $)$, laminin $\left(0.12 \mu \mathrm{g} / \mathrm{cm}^{2}\right.$; Roche Diagnostics) or collagen $\left(2.5 \mu \mathrm{g} / \mathrm{cm}^{2}\right.$, rat tail collagen type I; BD Biosciences, Bedford, Mass., USA). Cells were then allowed to attach undisturbed in a humidified incubator $\left(5 \% \mathrm{CO}_{2}, 37^{\circ} \mathrm{C}\right)$ for different incubation times ( $5 \mathrm{~min}, 10 \mathrm{~min}, 30 \mathrm{~min}$ ), after which unattached cells were removed by washing with PBS. To standardize the conditions, all the conditions at the same timepoint were added simultaneously to one microplate. The number of attached cells was quantified by assaying for DNA with a CyQUANT Cell Proliferation Assay Kit (Invitrogen) according to the manufacturer's protocol.

To achieve an in vitro situation more comparable to the in vivo situation after AMI, attachment of ASC to cardiac muscle cells and to fibronectin-coated cardiac muscle cells was investigated. Cardiomyoblasts (H9c2, p18; ATCC, Manassas, Va., USA) were seeded into 24-well culture dishes, at a density of 10,000 cells per well, and when wells were $70 \%$ confluent, cells were either coated with fibronectin $\left(0.5\right.$ or $\left.5.0 \mu \mathrm{g} / \mathrm{cm}^{2}\right)$ or remained uncoated. Then culture-expanded cells ( $\mathrm{p} 3-\mathrm{p} 7)$ from four donors were seeded into the culture dishes, at a density of 40,000 cells per well. Cells were allowed to attach undisturbed in a humidified incubator $\left(5 \% \mathrm{CO}_{2}, 37^{\circ} \mathrm{C}\right)$ for various incubation times ( $5 \mathrm{~min}, 10 \mathrm{~min}, 30 \mathrm{~min}$ ), after which the unattached cells were removed by washing with PBS. The cells were subsequently trypsinized, washed, centrifuged at $600 \mathrm{~g}$ for $5 \mathrm{~min}$, resuspended in $50 \mu \mathrm{l}$ PBS and incubated with anti-CD90 phycoerythrin-labelled antibody (1:20; BD Biosciences Pharmingen, San Diego, Calif., USA) for 30 min on ice. The percentage of CD90-positive cells (ASC) was quantified by using fluorescence-activated cell sorting (FACS) analysis (FACScaliber, Becton Dickinson, San Jose, Calif., USA).

Proliferation of ASC

To assess ASC proliferation on fibronectin-coated culture dishes, culture-expanded cells (p3-p6) from three donors were plated into 6-well culture plates, at a density of 25,000 cells per well, either coated with $5 \mu \mathrm{g} / \mathrm{cm}^{2}$ fibronectin or uncoated, in normal culture medium. After a 1-day incubation in a humidified incubator $\left(5 \% \mathrm{CO}_{2}, 37^{\circ} \mathrm{C}\right)$, unattached cells were removed by washing with PBS. Cells were then allowed to proliferate for various incubation times ( 0 days, 3 days, 6 days, 9 days). Cells were washed with PBS to remove dead cells. The amount of living cells removed by this washing was negligible $(<0.5 \%)$. The number of attached cells was quantified by assaying for DNA with a CyQUANT Cell Proliferation Assay Kit (Invitrogen) according to the manufacturer's protocol.

Myocardial tissue from infarction

Myocardial tissue from 27 autopsied patients who had died from AMI and from eight autopsied patients with no cardiac lesions of any kind was obtained from the Department of Pathology for authopsy, with approval of the ethics committee of the VU Medical Centre, Amsterdam. The use of left-over material after the pathological examination is completed, is part of the standard patient contract in our hospital. Heart tissue was sampled as soon as possible, within $24 \mathrm{~h}$ of death.

\section{Characterization of infarction phase}

Recent AMI was defined by using macroscopic (lactate dehydrogenase decolouration) and microscopic criteria to estimate infarct duration and the viability of cardiomyocytes in all myocardial tissue specimens (paraffin-waxembedded sections stained with haematoxylin and eosin). Clinical data with respect to the duration of the infarction corresponded to the time intervals of the various morphological phases of infarction. Jeopardized myocardium was characterized by the intensity of eosinophilic staining of involved myofibres, cell condensation, loss of nuclei and cross striation and was visualized by complement (C3d) staining. We defined heart tissue sections without microscopic changes but with macroscopic lactate dehydrogenase decolourization as a phase 1 infarct (3- to 12-h-old AMI), infiltration of polymorphonuclear leucocytes as a phase 2 infarct (12-h to 5-day-old AMI) and infiltration of lymphocytes and macrophages and fibrosis as a phase 3 
Table 1 Characterization of the different infarct phases used in the immunohistochemical study ( $L D H$ lactate dehydrogenase)

\begin{tabular}{|c|c|c|c|}
\hline $\begin{array}{l}\text { Infarction } \\
\text { phase }\end{array}$ & $\begin{array}{l}\text { Number } \\
\text { of patients }\end{array}$ & $\begin{array}{l}\text { Infarct } \\
\text { duration }\end{array}$ & Definition \\
\hline 0 & 8 & No infarction & Does not apply \\
\hline 1 & 11 & $3-12 \mathrm{~h}$ & $\begin{array}{l}\text { LDH decolourization, } \\
\text { without extravascular } \\
\text { neutrophilic granulocytes. }\end{array}$ \\
\hline 2 & 9 & $12 \mathrm{~h}-5$ days & $\begin{array}{l}\text { Extravascular neutrophilic } \\
\text { granulocytes. }\end{array}$ \\
\hline 3 & 7 & 5-14 days & $\begin{array}{l}\text { Granulation tissue } \\
\text { formation }\end{array}$ \\
\hline
\end{tabular}

infarct (5- to 15-day-old AMI; Krijnen et al. 2003). Table 1 shows the distribution of the various infarct phases among the different patients.

Immunohistochemistry

Myocardial tissue was fixed with $4 \%$ buffered formaldehyde and embedded in paraffin. Paraffin sections $(3-4 \mu \mathrm{m})$ were mounted on glass slides, dried, deparaffinized, rehydrated, and then used for immunohistochemistry. Sections were stained for fibronectin. Serial sections were stained for complement factor $\mathrm{C} 3 \mathrm{~d}$ to define the microscopical infarction area (Krijnen et al. 2003). All antibodies used were from DakoCytomation (Glostrup, Denmark).

For C3d staining, antigen retrieval was performed by boiling sections in $10 \mathrm{mM}$ sodium citrate buffer, $\mathrm{pH} 6.0$, for $10 \mathrm{~min}$ in a microwave oven. Sections were pre-incubated with normal swine serum (1:10; DakoCytomation) for 10 min at room temperature, followed by an incubation with rabbit antibodies against human $\mathrm{C} 3 \mathrm{~d}(1: 1,000)$ for $1 \mathrm{~h}$ at room temperature. The sections were then washed with PBS and incubated with biotin-conjugated swine-anti-rabbit antibodies (1:300) for $30 \mathrm{~min}$, washed in PBS and incubated with streptavidin-biotin complex/horseradish peroxidase (1:200) for $1 \mathrm{~h}$. Staining was visualized by using 3,3'-diaminobenzidine (DAB; $0.1 \mathrm{mg} / \mathrm{ml}, 0.02 \% \mathrm{H}_{2} \mathrm{O}_{2}$ ).

For fibronectin staining, antigen retrieval was performed by incubating the sections with $0.1 \%$ pepsine- $\mathrm{HCl}$ for $30 \mathrm{~min}$ at $37^{\circ} \mathrm{C}$. Sections were incubated with rabbit antibodies against human fibronectin $(1: 18,000)$ for $1 \mathrm{~h}$ at room temperature, followed by incubation with $100 \mu \mathrm{l}$ envision (ready for use kit, anti-Mouse IgG and anti-Rabbit $\mathrm{IgG})$ for $30 \mathrm{~min}$ at room temperature. Staining was visualized with envision DAB (DakoCytomation). Finally, the sections were counterstained with haematoxylin, dehydrated and cover-slipped. Control sections were incubated with PBS instead of the primary antibody.

All slides were judged and scored for infarct age and anatomical localization of fibronectin and $\mathrm{C} 3 \mathrm{~d}$, as visualized by immunohistochemical staining. The border-zone of the infarct was defined as the area surrounding the microscopic infarction area, as characterized by C3d staining. Since only the fibronectin on the plasma membrane and in the ECM are available for ASC attachment, fibronectin deposition was scored separately for the ECM, plasma membrane and intracellular components (nucleus and cytoplasm). The extent of the fibronectin deposits was determined by quantifying the mean surface area occupied by cardiomyocytes positive for fibronectin and expressed as a percentage of the total surface area of the sections in the infarcted region, border-zone and non-infarcted areas. Areas were scored as negative (0), $1 \%-5 \%$ of the cells positive (1), $6 \%-25 \%$ positive (2), $26 \%-50 \%$ positive (3), $51 \%-75 \%$ positive (4) or $76 \%-100 \%$ positive (5). Since positivity of fibronectin in the ECM is difficult to quantify, fibronectin staining in ECM was related to its intensity score as follows: negative (0), minor positive (1), intermediate positive (2) or strongly positive (3).

\section{Statistics}

Statistics were performed with the SPSS statistics program (Windows version 9.0) and Graphpad Prism (version 4). Attachment and proliferation data were analysed by using Repeated Measures. Fibronectin accumulation was analysed by the Kruskal Wallis and the Dunn's Multiple Comparison Test. A $P$-value of less than 0.05 was considered to be significant.

\section{Results}

Attachment and proliferation of ASCs on fibronectin

To investigate the attachment of ASC to various ECM molecules, the percentage of ASCs adhering to laminin, fibronectin, collagen-1 and uncoated culture wells was analysed. We monitored the number of ASCs in the culture wells and compared this with the numbers of cells in uncoated culture wells. As shown in Fig. 1, after 5 and $10 \mathrm{~min}$ of incubation, significantly higher numbers of ASC were detected on fibronectin-coated culture wells as compared with the uncoated culture wells $(P<0.05)$. This effect was dose-dependent, since a lower concentration of fibronectin $\left(0.5 \mu \mathrm{g} / \mathrm{cm}^{2}\right.$ instead of $\left.5.0 \mu \mathrm{g} / \mathrm{cm}^{2}\right)$ did not increase ASC attachment. Laminin and collagen-1 did not significantly affect ASC attachment, although collagen-1 showed a trend towards increased attachment of ASC. After $30 \mathrm{~min}$, a plateau level seemed to be reached for all conditions. This suggested that ASC adhered more rapidly to fibronectin than to laminin, collagen or uncoated culture wells. 
a

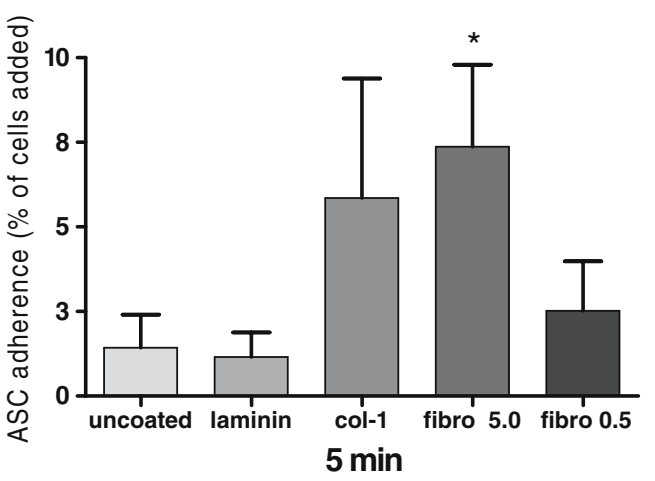

b

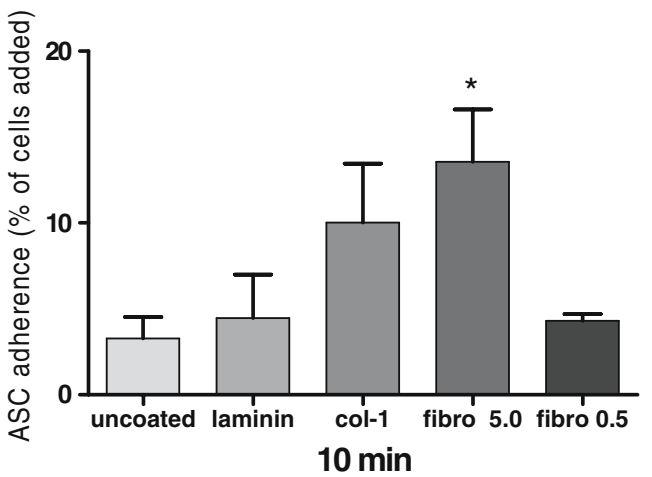

C

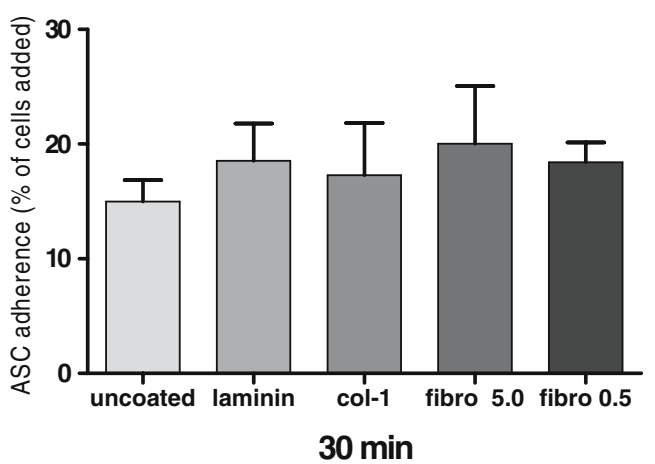

Fig. 1 ASC adherence to laminin-coated, collagen-1 (col-1)-coated and fibronectin (fibro)-coated ( 5 and $0.5 \mu \mathrm{g} / \mathrm{cm}^{2}$ ) and uncoated culture wells monitored with time. Numbers of adhered ASCs were quantified after 5 (a), 10 (b) and 30 (c) min of attachment. Results are expressed as the percentage of applied cells. Error bars represent means \pm SEM $(n=4, * P<0.05$, Repeated measures)

To investigate the kinetics of ASC attachment in a setting more comparable to the in vivo situation after AMI, the percentage of ASCs adhering to fibronectin-coated and uncoated cardiac muscle cells was monitored with time. Numbers of adhered ASCs were quantified after 5, 10 and 30 min of attachment and are shown as the percentage of total cells applied in Fig. 2. ASC rapidly adhered to the fibronectin-coated cardiac muscle cells. This rapid attachment was most prominent after 5 min of incubation, when
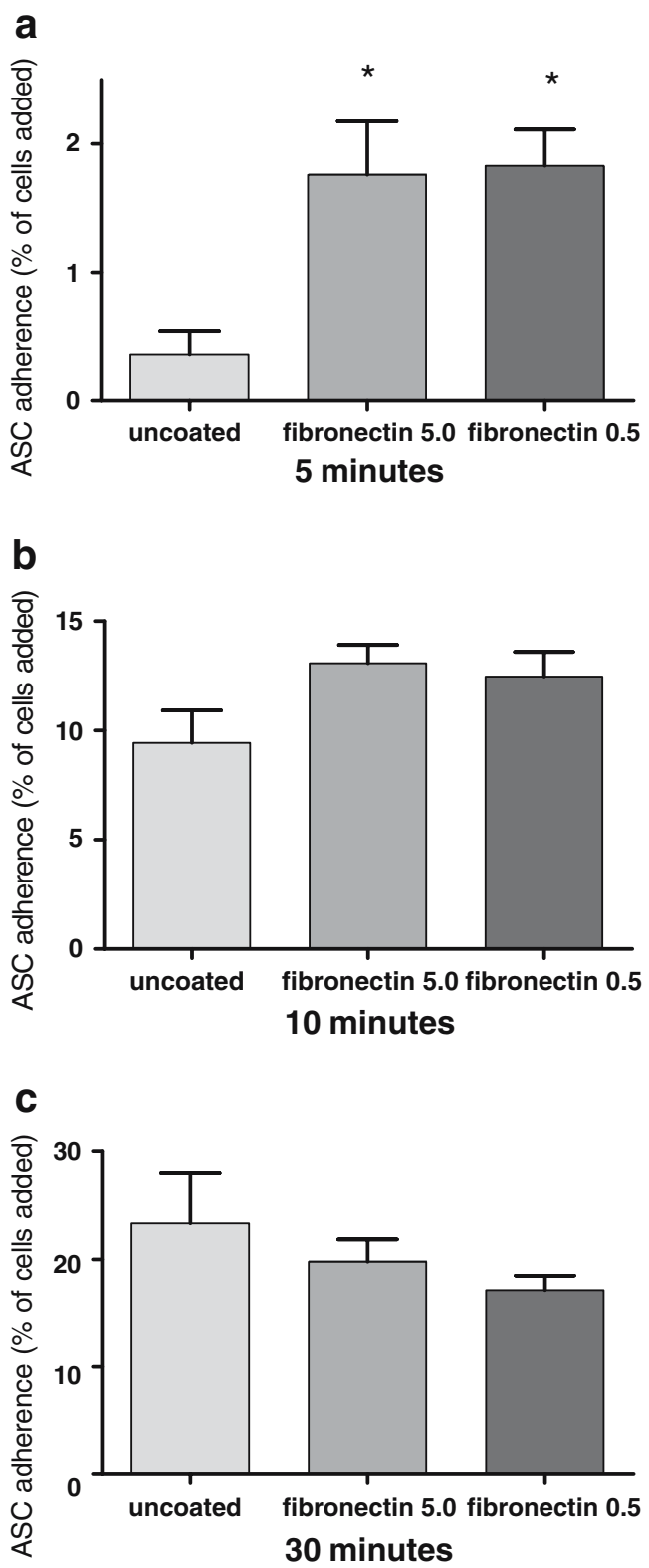

Fig. 2 Kinetics of ASC adherence to fibronectin-coated (5 and $0.5 \mu \mathrm{g} / \mathrm{cm}^{2}$ ) and uncoated cardiac muscle cells monitored with time. Numbers of adhered ASCs were quantified after 5 (a), 10 (b) and 30 (c) min of attachment. Results are expressed as the percentage of applied cells. Error bars represent means \pm SEM $(n=4, * P<0.05$, Repeated measures)

5 times more ASC attached to the fibronectin-coated cells than to the uncoated cells $(P<0.05)$. This effect was independent of the dose of fibronectin, since the ASC also attached rapidly to the cardiac muscle cells coated with a lower concentration of fibronectin $\left(0.5 \mu \mathrm{g} / \mathrm{cm}^{2}\right.$ instead of $5.0 \mu \mathrm{g} / \mathrm{cm}^{2}$ ). On the uncoated cardiac muscle cells, however, attachment was limited when compared with the fibronectin-coated cells and increased only gradually the first $10 \mathrm{~min}$. For all conditions, a plateau level was reached after $30 \mathrm{~min}$ of attachment. These findings suggested that 


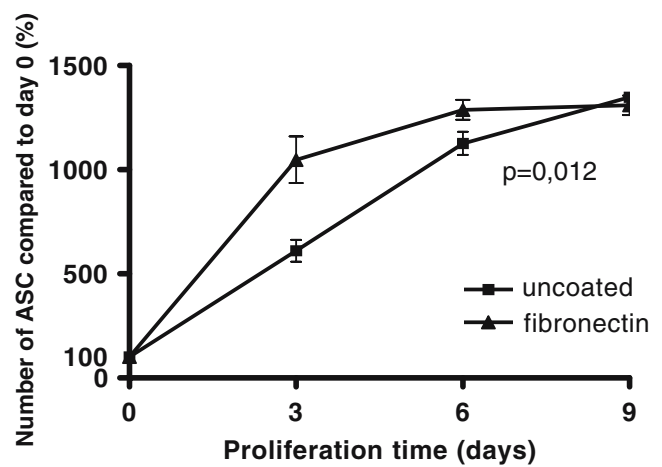

Fig. 3 Kinetics of ASC proliferation on fibronectin-coated $\left(5 \mu \mathrm{g} / \mathrm{cm}^{2}\right)$ and uncoated culture wells. Numbers of adhered ASCs were quantified after 0, 3, 6 and 9 days of culture by using the CyQUANT cell proliferation assay. Results are expressed as percentage of cells, compared to day 0 , both for the fibronectin-coated and uncoated wells. Error bars represent means \pm SEM. $(n=3, p=0,012$, Repeated measures)

ASC attached more rapidly on fibronectin-coated cardiac muscle cells than to uncoated cardiac muscle cells.

To study the proliferation of ASCs on fibronectin, ASCs were seeded in fibronectin-coated culture wells. Unattached cells were washed away after $24 \mathrm{~h}$ (day 0). We monitored the number of ASCs in the culture wells with time (days 0 , $3,6,9)$ and compared this with the numbers of cells in uncoated culture wells. Significantly higher numbers of ASC were detected on fibronectin-coated culture wells compared with the uncoated culture wells during the 9-day culture period ( $P=0.012$, Repeated measures, $n=3$; Fig. 3 ).

Fibronectin accumulation after infarction

Fibronectin accumulation after myocardial infarction was investigated in heart sections from 35 patients, representing various infarction periods (no infarction, infarction of 3$12 \mathrm{~h}$ old, $12 \mathrm{~h}-5$ days old, and 5-14 days old). To define jeopardized cardiomyocytes and thus the microscopical infarction area, we stained serial sections for complement factor C3d (Fig. 4c). Fibronectin was found not only in cardiomyocytes (plasma membrane, cytoplasm and nucleus; Fig. 4a), but also in the ECM (Fig. 4b). Fibronectin colocalized with complement factor $\mathrm{C} 3 \mathrm{~d}$ but fibronectin deposition was also found in the border-zone adjacent to the infarction area (complement-negative). To analyse
Fig. 4 Localization of fibronectin in myocardial infarction of the human heart. Fibronectin accumulation after myocardial infarction was investigated in heart sections representing different infarction periods. a High power view of fibronectin deposition in infarct phase 2 . Fibronectin depositions were found on the plasma membrane (arrow I), in the nucleus (arrow $I I$ ) and in the cytoplasm (arrow III) of jeopardized cardiomyocytes. b Fibronectin depositions in infarct phase 3 in the extracellular matrix (ECM; arrow $I V)$. c C3d deposition in infarct phase 2 (+ jeopardized cardiomyocytes, i.e. complement-positive cells, - complementnegative cells). d Fibronectin colocalization within C3d-positive areas in a serial section from the same patient as in $\mathbf{c}$, in infarct phase 2. As a control, AMI sections were incubated with PBS instead of $\mathrm{mAb}$ and gave no positive staining (not shown)
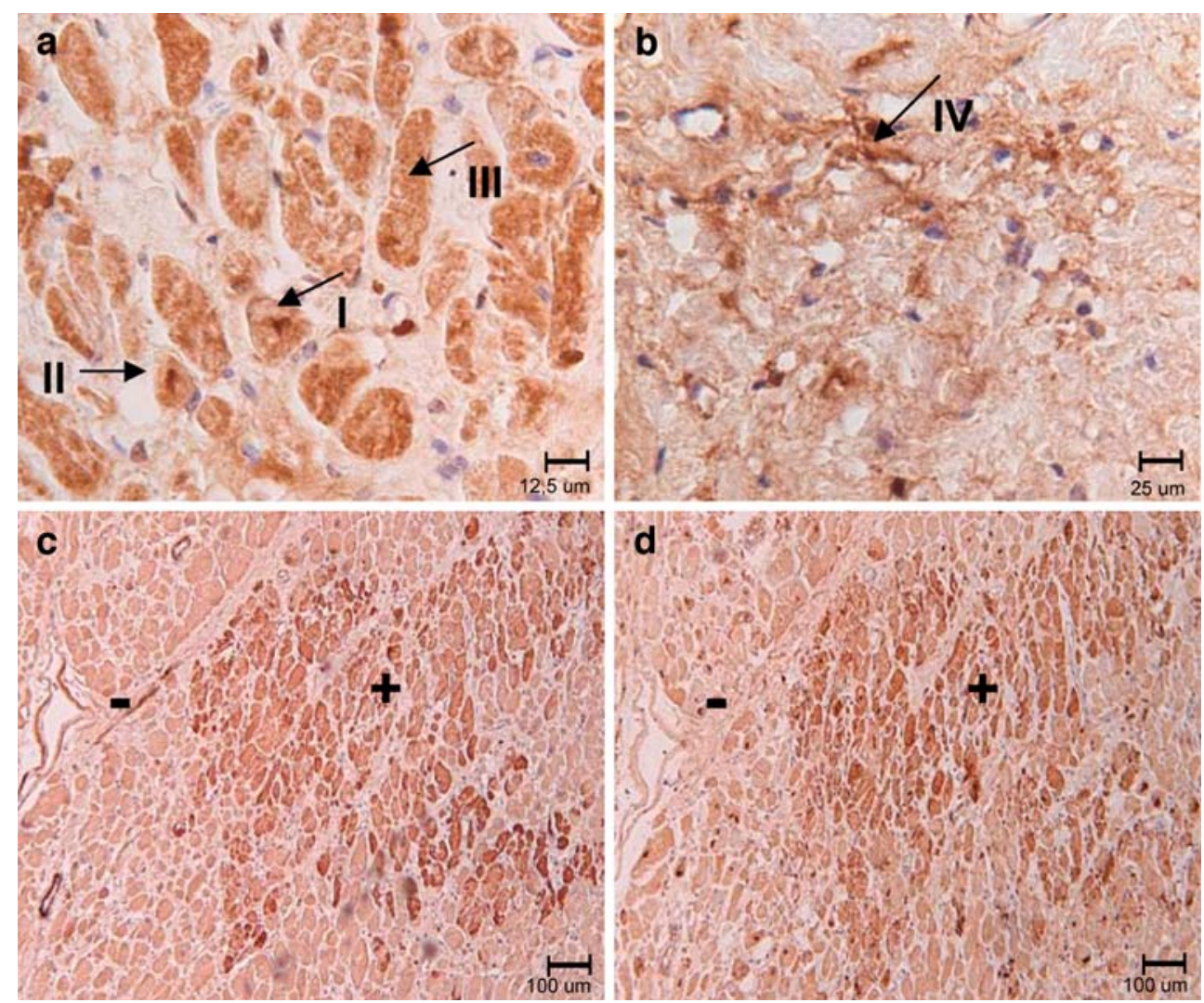


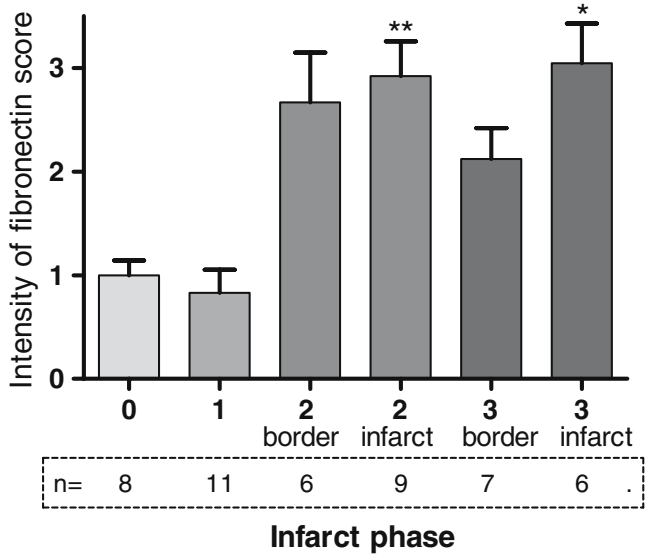

Fig. 5 Fibronectin deposition in the ECM of the human heart after myocardial infarction. Intensity of the fibronectin deposition in the ECM was scored and compared with that of the non-infarcted heart (stadium 0). Areas were scored negative (0), minor positive (1), intermediate positive (2) or strongly positive (3). Error bars represent means \pm SEM $(* P<0.05, * * P<0.01)$

fibronectin depositions in the human heart after myocardial infarction, we scored all sections for the extent and the anatomical localization of fibronectin depositions. Notably, in AMI phase 1, the border-zone and infarcted area could not be analysed as such with the slides from the macroscopical infarction area, since it was not possible to identify a microscopical infarction area clearly at this early phase, as complement was then negative. As shown, the intensity of fibronectin depositions in the ECM (Fig. 5) was significantly increased at the site of myocardial infarction of AMI phases $2(P<0.01)$ and $3(P<0.05)$ compared with the uninfarcted heart. The extent of fibronectin deposition was also increased in the border-zone of phases 2 and 3; however, this increase was not statistically significant. In phase 1 infarction and in the uninfarcted areas, no increase in ECM fibronectin intensity score was found, when compared with uninfarcted hearts (not shown).

We subsequently scored fibronectin positivity in the cardiomyocytes. The extent of fibronectin deposition was significantly increased in the infarcted area of AMI phase 2, compared with controls, at the plasma membrane $(P<0.05)$, in the cytoplasm $(P<0.001)$ and in the nucleus $(P<0.05)$. Fibronectin depositions were increased not only in the infarcted area, but also in the border-zone of phase 2; however, this increase was only statistically significant in the nucleus when compared with the non-infarcted heart. In AMI phase 3, no cardiomyocytes in the infarction area could be analysed since this area no longer contains cardiomyocytes in this stadium, but only granulation tissue. The extent of fibronectin deposition was still significantly a

Membrane

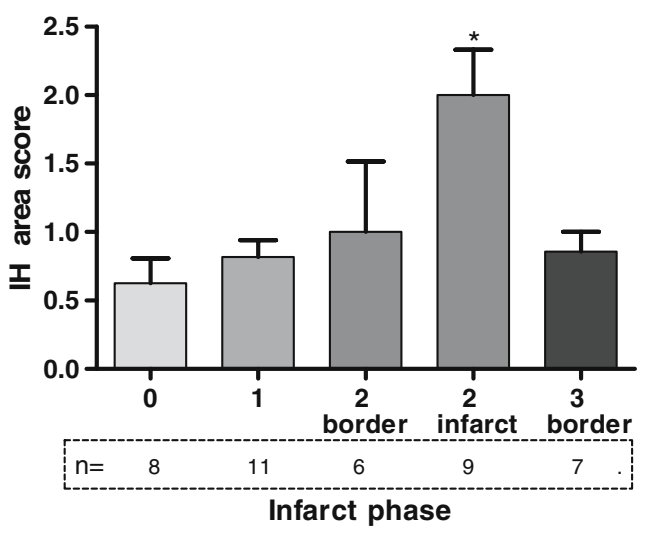

b
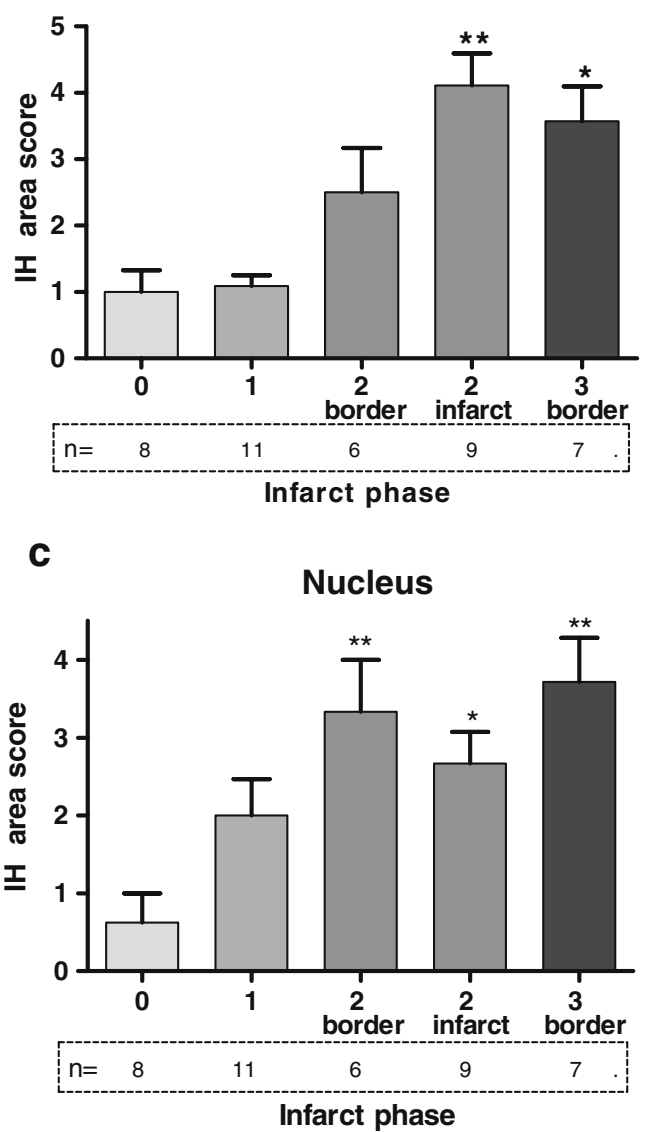

Fig. 6 Fibronectin deposition in cardiomyocytes in the human heart after myocardial infarction ( $I H$ immunohistochemical). a Area of fibronectin deposition in the plasma membrane. b Area of fibronectin deposition in the cytoplasm. c Area of fibronectin deposition in the nucleus. Areas are scored from 0 for no fibronectin-positive cells up until 5 for $75 \%-100 \%$ fibronectin-positive cells. Error bars represent means $\pm \mathrm{SE}\left(* \mathrm{P}<0.05,{ }^{*} * \mathrm{P}<0.01\right)$ (Phase $0: n=8$, phase $1: n=11$, phase 2 border: $n=6$, phase 2 infarct: $n=9$, phase 3 border: $n=7$ ) 
increased in the border-zone of AMI phase 3 in the nucleus and cytoplasm but was not positive on the plasma membrane (Fig. 6a). Neither in AMI phase 1 (Fig. 6) nor in non-infarcted areas (not shown) was an increase in fibronectin positivity found in the cardiomyocytes when compared with controls (Fig. 6).

\section{Discussion}

We hypothesized that accumulation of fibronectin in the heart after MI might improve the fate of ASC after transplantation in the heart. Therefore, we have studied the effect of this protein on the attachment and proliferation of ASC in vitro. In addition, we have investigated the time course and the localization of the accumulation of fibronectin after myocardial infarction in the human infarcted heart. We have found that ASC attachment and proliferation on fibronectin-coated plates is significantly increased compared with that on uncoated plates (early attachment: $P<0.05$, proliferation: $P=0.009$, Repeated measures, $n=4$ ) and that attachment of ASC to cardiac muscle cells is significantly increased when cells are coated with fibronectin $\left(0.5 \mu \mathrm{g} / \mathrm{cm}^{2}\right.$ and $5.0 \mu \mathrm{g} / \mathrm{cm}^{2}$ ), after $5 \mathrm{~min}$ of attachment. In the ECM of the human heart, fibronectin depositions are significantly increased at AMI phase 2 and phase 3 in the infarction area, whereas fibronectin deposition in the cytoplasm, at the plasma membrane and in the nucleus of cardiomyocytes is significantly increased at AMI phase 2, but not in AMI phase 3 , except for depositions in the nucleus.

When culture wells are coated with fibronectin, we have found an increased attachment of ASC when compared with uncoated plates, even though ASC are mesenchymal stem cells that are defined by their strong attachment to plastic culture wells (Wagner et al. 2005). We have also found that neither laminin nor collagen-1 significantly increases the attachment of ASC, unlike fibronectin, which does cause an increase. These findings are comparable with studies of Ogura et al. (2004) and Cool and Nurcombe (2005), in which an increased attachment of human bone-marrowderived MSC to fibronectin-coated culture plates has been found when compared with albumin-coated or other ECMcoated culture plates. Ogura et al. (2004) have also reported that attachment to fibronectin is most prominent within the first $20 \mathrm{~min}$ of incubation. We now have shown that fibronectin also improves the attachment of ASC.

In an experiment mimicking the in vivo situation after a myocardial infarction, we have demonstrated that fibronectin also increases the attachment of ASC to cardiac muscle cells, even when a relatively low concentration of fibronectin is used. These results are in agreement with our hypothesis that fibronectin depositions will also increase stem cell attachment in vivo, independent of fibronectin concentration, underlining the importance of fibronectin in stem cell transplantation.

In this study, we have additionally demonstrated a significant increase in the proliferation of ASC cultured in fibronectin-coated wells, compared with proliferation in uncoated culture wells $(P=0.012)$. This effect is most prominent during the first 5 days of culture; thereafter, the cells grow confluently and the effect diminishes. Cool and Nurcombe (2005) have found no significant effect of fibronectin on proliferation, although a trend is visible; this might be caused by the timepoint of their study, since they have only measured the difference in cell numbers at day 7 , or could be related to the source of stem cells.

Since the presence of fibronectin promotes ASC attachment and proliferation in vitro in our study, we have hypothesized that the presence of fibronectin in the heart after myocardial infarction might positively affect stem cell adhesion and proliferation at the site of injury. As such, stem cell therapy would be most efficient when fibronectin depositions are high. We have found an increase in the extent of fibronectin depositions in cardiomyocytes during AMI phase 2, whereas fibronectin deposition in the ECM is significantly increased in the infarction area during AMI phase 2 and phase 3, when compared with the uninfarcted heart.

These results are comparable with the findings of several animal studies, in which increased fibronectin mRNA expression has been demonstrated, together with increased fibronectin deposition in the infarcted area as early as the first day after infarct induction (Carlyle et al. 1997; Froen and Larsen 1995; Knowlton et al. 1992; Shekhonin et al. 1990; Ulrich et al. 1997). Moreover, several studies have shown increased deposition of fibronectin in the infarction area after MI in human (Hu et al. 1996; Ishikawa et al. 2000, 2003; Ortmann et al. 2000; Willems et al. 1996). However, none of these studies have scored the fibronectin depositions as accurately as we have during the different infarction phases, i.e. by using complement to define the microscopic infarction area, by differentiating between infarction area and border-zone and by separately scoring the ECM and the various anatomical locations in the cells.

We have studied the various anatomical locations of fibronectin depositions separately, since theoretically only fibronectin on the plasma membrane and in the ECM should play a direct role in stem cell attachment. Although fibronectin has been detected on the ECM and the plasma membrane of cardiomyocytes, depositions in the cytoplasm and the nuclei are more widespread than on the plasma membrane. These strong depositions in the nucleus and cytoplasm have also been reported by Ishikawa et al. (2000); 
however, they have only described these nuclear depositions and not scored them.

Notably, we have found that the extent of fibronectin depositions in the heart is only increased in the infarcted area and the border-zone, and not in the non-infarcted areas. This is an important observation, since stem cell attachment and differentiation is only desirable in the infarcted area and the area surrounding it for stem cell therapy. In accordance with this finding, Tran et al. (2006) have indeed shown that rat bone marrow MSC are retained better in the infarcted area, when compared with the intact myocardium.

Several other studies have also investigated the time frame after MI with respect to when best to apply stem cell therapy, both in animal models and human stem cell transplantation studies, by investigating molecular events and stem cell retention at the site of infarction (Bermejo et al. 2006; Lu et al. 2004; Ma et al. 2005). These studies suggest that stem cell therapy should neither be applied during the acute inflammation phase (within 1 day after infarction), nor after a period longer than 2 weeks when scar tissue has been formed. In agreement with this suggestion, our results indicate that a putative effect of fibronectin on stem cell therapy can only be achieved when stem cell therapy is applied more than $12 \mathrm{~h}$ but within 14 days after infarction.

In conclusion, we have shown, for the first time, that fibronectin improves ASC attachment and proliferation. To achieve a positive effect of fibronectin on stem cell therapy after AMI in the heart, this therapy should be applied when fibronectin depositions in the heart are high. We have accurately scored fibronectin deposition in the human heart after AMI and found that the fibronectin intensity score significantly increases from $12 \mathrm{~h}$ after MI in both the infarction area and the border-zone.

\section{References}

Azarnoush K, Maurel A, Sebbah L, Carrion C, Bissery A, Mandet C, Pouly J, Bruneval P, Hagege AA, Menasche P (2005) Enhancement of the functional benefits of skeletal myoblast transplantation by means of coadministration of hypoxia-inducible factor 1alpha. J Thorac Cardiovasc Surg 130:173-179

Bermejo J, Segovia J, Alfonso F (2006) Summary of the clinical studies reported in the scientific session of the American Heart Association 2005 (Dallas, Texas, USA, 13-16 November 2005). Rev Esp Cardiol 59:143-153

Carlyle WC, Jacobson AW, Judd DL, Tian B, Chu C, Hauer KM, Hartman MM, McDonald KM (1997) Delayed reperfusion alters matrix metalloproteinase activity and fibronectin mRNA expression in the infarct zone of the ligated rat heart. J Mol Cell Cardiol 29:2451-2463

Chastain SR, Kundu AK, Dhar S, Calvert JW, Putnam AJ (2006) Adhesion of mesenchymal stem cells to polymer scaffolds occurs via distinct ECM ligands and controls their osteogenic differentiation. J Biomed Mater Res [A] 78:73-85

Cool SM, Nurcombe V (2005) Substrate induction of osteogenesis from marrow-derived mesenchymal precursors. Stem Cells Dev 14:632-642

Deten A, Holzl A, Leicht M, Barth W, Zimmer HG (2001) Changes in extracellular matrix and in transforming growth factor beta isoforms after coronary artery ligation in rats. J Mol Cell Cardiol 33:1191-1207

Fraser JK, Schreiber RE, Zuk PA, Hedrick MH (2004) Adult stem cell therapy for the heart. Int J Biochem Cell Biol 36:658-666

Froen JF, Larsen TH (1995) Fibronectin penetration into heart myocytes subjected to experimental ischemia by coronary artery ligation. Acta Anat (Basel) 152:119-126

Heng BC, Haider HK, Sim EK, Cao T, Ng SC (2004) Strategies for directing the differentiation of stem cells into the cardiomyogenic lineage in vitro. Cardiovasc Res 62:34-42

$\mathrm{Hu}$ BJ, Chen YC, Zhu JZ (1996) Immunohistochemical study of fibronectin for postmortem diagnosis of early myocardial infarction. Forensic Sci Int 78:209-217

Ishikawa Y, Akasaka Y, Ishii T, Itoh K, Masuda T, Zhang L, Kiguchi $H$ (2000) Sequential changes in localization of repair-related proteins (heat shock protein 70, ubiquitin and vascular endothelial growth factor) in the different stages of myocardial infarction. Histopathology 37:546-554

Ishikawa Y, Akasaka Y, Ishii T, Yoda-Murakami M, Choi-Miura NH, Tomita M, Ito K, Zhang L, Akishima Y, Ishihara M, Muramatsu M, Taniyama M (2003) Changes in the distribution pattern of gelatin-binding protein of $28 \mathrm{kDa}$ (adiponectin) in myocardial remodelling after ischaemic injury. Histopathology 42:43-52

Khalil ME, Basher AW, Brown EJ Jr, Alhaddad IA (2001) A remarkable medical story: benefits of angiotensin-converting enzyme inhibitors in cardiac patients. J Am Coll Cardiol 37:1757-1764

Knowlton AA, Connelly CM, Romo GM, Mamuya W, Apstein CS, Brecher P (1992) Rapid expression of fibronectin in the rabbit heart after myocardial infarction with and without reperfusion. J Clin Invest 89:1060-1068

Krijnen PA, Meischl C, Hack CE, Meijer CJ, Visser CA, Roos D, Niessen HW (2003) Increased Nox2 expression in human cardiomyocytes after acute myocardial infarction. J Clin Pathol 56:194-199

Lange RA, Hillis LD (2002) Reperfusion therapy in acute myocardial infarction. N Engl J Med 346:954-955

Lu L, Zhang JQ, Ramires FJ, Sun Y (2004) Molecular and cellular events at the site of myocardial infarction: from the perspective of rebuilding myocardial tissue. Biochem Biophys Res Commun 320:907-913

Ma J, Ge J, Zhang S, Sun A, Shen J, Chen L, Wang K, Zou Y (2005) Time course of myocardial stromal cell-derived factor 1 expression and beneficial effects of intravenously administered bone marrow stem cells in rats with experimental myocardial infarction. Basic Res Cardiol 100:217-223

Malek S, Kaplan E, Wang JF, Ke Q, Rana JS, Chen Y, Rahim BG, Li M, Huang Q, Xiao YF, Verheugt FW, Morgan JP, Min JY (2006) Successful implantation of intravenously administered stem cells correlates with severity of inflammation in murine myocarditis. Pflügers Arch 452:268-275

Mishra PK (2005) Stem cell therapy for myocardial regeneration: creating hype ignoring reality. Eur J Cardiothorac Surg 28:909910

Morishita N, Kusachi S, Yamasaki S, Kondo J, Tsuji T (1996) Sequential changes in laminin and type IV collagen in the infarct 
zone-immunohistochemical study in rat myocardial infarction. Jpn Circ J 60:108-114

Oedayrajsingh-Varma MJ, van Ham SM, Knippenberg M, Helder MN, Klein-Nulend J, Schouten TE, Ritt MJ, van Milligen FJ (2006) Adipose tissue-derived mesenchymal stem cell yield and growth characteristics are affected by the tissue-harvesting procedure. Cytotherapy 8:166-177

Ogura N, Kawada M, Chang WJ, Zhang Q, Lee SY, Kondoh T, Abiko Y (2004) Differentiation of the human mesenchymal stem cells derived from bone marrow and enhancement of cell attachment by fibronectin. J Oral Sci 46:207-213

Orlic D, Kajstura J, Chimenti S, Limana F, Jakoniuk I, Quaini F, Nadal-Ginard B, Bodine DM, Leri A, Anversa P (2001) Mobilized bone marrow cells repair the infarcted heart, improving function and survival. Proc Natl Acad Sci USA 98: 10344-10349

Ortmann C, Pfeiffer H, Brinkmann B (2000) A comparative study on the immunohistochemical detection of early myocardial damage. Int J Legal Med 113:215-220

Salasznyk RM, Williams WA, Boskey A, Batorsky A, Plopper GE (2004) Adhesion to vitronectin and collagen i promotes osteogenic differentiation of human mesenchymal stem cells. J Biomed Biotechnol 2004:24-34

Shekhonin BV, Guriev SB, Irgashev SB, Koteliansky VE (1990) Immunofluorescent identification of fibronectin and fibrinogen/ fibrin in experimental myocardial infarction. J Mol Cell Cardiol 22:533-541

Smits AM, van Vliet P, Hassink RJ, Goumans MJ, Doevendans PA (2005) The role of stem cells in cardiac regeneration. J Cell Mol Med 9:25-36

Strauer BE, Brehm M, Zeus T, Kostering M, Hernandez A, Sorg RV, Kogler G, Wernet P (2002) Repair of infarcted myocardium by autologous intracoronary mononuclear bone marrow cell transplantation in humans. Circulation 106:1913-1918

Tate MC, Shear DA, Hoffman SW, Stein DG, Archer DR, LaPlaca MC (2002) Fibronectin promotes survival and migration of primary neural stem cells transplanted into the traumatically injured mouse brain. Cell Transplant 11:283-295

Tran N, Li Y, Maskali F, Antunes L, Maureira P, Laurens MH, Marie PY, Karcher G, Groubatch F, Stoltz JF, Villemot JP (2006) Shortterm heart retention and distribution of intramyocardial delivered mesenchymal cells within necrotic or intact myocardium. Cell Transplant 15:351-358

Ulrich MM, Janssen AM, Daemen MJ, Rappaport L, Samuel JL, Contard F, Smits JF, Cleutjens JP (1997) Increased expression of fibronectin isoforms after myocardial infarction in rats. $\mathrm{J}$ Mol Cell Cardiol 29:2533-2543

van der Loo JC, Xiao X, McMillin D, Hashino K, Kato I, Williams DA (1998) VLA-5 is expressed by mouse and human long-term repopulating hematopoietic cells and mediates adhesion to extracellular matrix protein fibronectin. J Clin Invest 102:1051-1061

Voermans C, Gerritsen WR, dem Borne AE, van der Schoot CE (1999) Increased migration of cord blood-derived CD34+ cells, as compared to bone marrow and mobilized peripheral blood CD34+ cells across uncoated or fibronectin-coated filters. Exp Hematol 27:1806-1814

Wagner W, Wein F, Seckinger A, Frankhauser M, Wirkner U, Krause U, Blake J, Schwager C, Eckstein V, Ansorge W, Ho AD (2005) Comparative characteristics of mesenchymal stem cells from human bone marrow, adipose tissue, and umbilical cord blood. Exp Hematol 33:1402-1416

Wang QD, Sjoquist PO (2006) Myocardial regeneration with stem cells: pharmacological possibilities for efficacy enhancement. Pharmacol Res 53:331-340

Wijelath ES, Rahman S, Murray J, Patel Y, Savidge G, Sobel M (2004) Fibronectin promotes VEGF-induced CD34 cell differentiation into endothelial cells. J Vasc Surg 39:655-660

Willems IE, Arends JW, Daemen MJ (1996) Tenascin and fibronectin expression in healing human myocardial scars. J Pathol 179:321-325

Zhang M, Methot D, Poppa V, Fujio Y, Walsh K, Murry CE (2001) Cardiomyocyte grafting for cardiac repair: graft cell death and anti-death strategies. J Mol Cell Cardiol 33:907-921 